\title{
Memoria incandescente del mar
}

\section{Xilberto Loera-Núñez}

\footnotetext{
斤 ntima y reflexiva, la obra que el joven artista toluqueño Xilberto Loera Núñez nos regala en este número se decanta por ofrecer una visión personalísima del tiempo y la memoria. En sus trazos se vislumbran los fragmentos de una materialidad líquida y una palpitante añoranza del movimiento. La mirada del espectador se vuelca sobre los tonos azules y violáceos, rosas y grises, naranjas y negruzcos que habitan los páramos de cada cuadro.

Obras que oscilan entre una visión clásica y cierta irreverencia del arte callejero, la propuesta del mexiquense pretende ir más allá de lo convencional y crear un lenguaje propio que se valga de una mixtura de formas y técnicas que no respondan a algo más que a su intencionalidad estética. Retratos de lo humano, hay en estos trabajos un dejo de ternura y una búsqueda del otro que convierten al lienzo en un puente entre quien narra y quien recuerda, entre el que ilustra y el que contempla.

El mar y sus arcanos, todo lo que hay en él de mítico y cotidiano, se dibuja como fondo de cada escena. Interpretar el silencio (2021), Mira el reflejo de mi cuerpo (2021) y Mar incendiado (2021) son una provocación a los sentidos y a la inteligencia que buscan convertirse en el inicio de un ejercicio exegético donde el arte y el yo se midan de frente. Los paisajes desérticos, informes, aparecen esporádicamente, siempre cobijados por un manto cargado de nubes donde las capas de pintura, espesas, avasallantes, dan eco a nuestra pesadumbre interior. Es el caso de Extremo y fin de la tierra prometida (2021), El agua y sus presagios (2021) y Fuego (2021).
} 
Emergiendo de la tierra, confundiéndose con ella, pequeñas bestias invocan la animalidad del mar. Los habitantes de Retrato de la langosta (2021) y Crustáceo de agua dulce bailando alrededor del fuego (2021) se deslizan en una salvaje danza que recuerda que no hay nada muerto en las fértiles arenas de las playas. Debajo de cada piedra, tras cada minúsculo arbusto, la vida surge vibrante e impone su propia cadencia frente al silencio y la quietud del entorno. Mención aparte merecen Perro de agua contemplando tierra firme (2021) y Perro de mar tomando el sol (2020), animales, esta vez domésticos que, como nosotros, se detienen frente a lo inconmensurable y, ante la imposibilidad de entenderlo, optan por el recogimiento y el deleite.

La serie Mar incendiado constituye también una exploración de ese mar mujer primigenio, cuyas líneas ondulantes se estremecen al ritmo de los óleos y el delicado tejido de la tela. Las obras Cuerpo de agua (2021), Madre mar (Chalchiutlicue) (2021), Anochece en el mar (2021), Los gestos del coral (2021), Flores que flotan (2021), Recuerdo de una ciudad gris (2021), Las dos caras del mar (2020), Bruma (2020), Tres (2020) y Xochipilli bajo el mar (2020) son, así, representaciones arquetípicas del eterno femenino.

En su mayor parte desnudas, las mujeres retratadas por Xilberto Loera encarnan un impulso vital que estalla en el florecimiento de la naturaleza. Quietas, ausentes, las protagonistas de estas aventuras oníricas parecen sumergirse en el pasado con nostalgia y sin prisas, como si en los pliegues de su piel descansara la sabiduría de los siglos y el sosiego de las antiguas divinidades.

La contraparte de estas figuras femeninas la constituyen Resistencia superficial (2021), Fuego (2021), Sal que sale del agua (2021), Flores de espuma y la mano que las obsequia (2020), El agua del cuerpo (2021) y El sueño de la langosta (2020), donde se nos muestra al hombre creador que cultiva con su trabajo los frutos de la playa. Los cuerpos masculinos, mucho menos idílicos y más terrenales que los de sus compañeras, dejan entrever el esfuerzo físico, la extenuante labor de quien coloniza y seduce los territorios oceánicos.

Ellos, fuego y tierra; ellas, agua y aire, se buscan sin descanso hasta hallarse en Objeto en movimiento tocando el agua (2021), Aprender a nadar (2020), Semilla compartida (2020) y Atardecer clásico (2021). Este encuentro, tan violento como dulce, salvador y fulminante, es el que da nombre a la serie. Y es que si hay algo que pueda trastocar el gélido sino del mar, incendiándolo, es el amor, esa sed infinita y atemporal del otro que se calma, aunque momentáneamente, en el roce de las manos y la calidez del beso. 


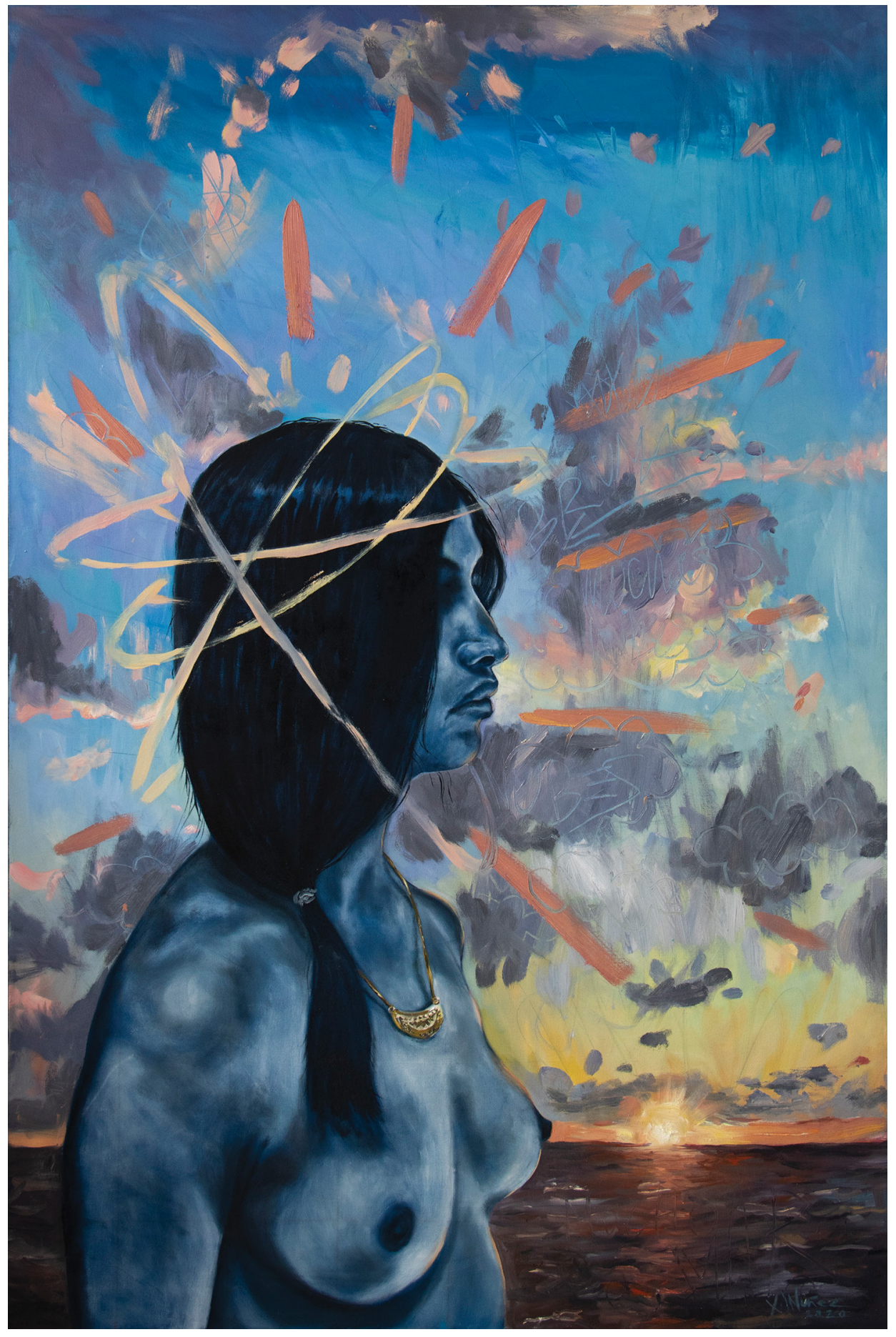

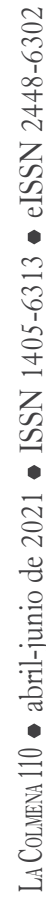

Bruma, de la serie Mar incendiado (2020). Óleo sobre lino: Xilberto Loera-Núñez. Prohibida su reproducción en obras derivadas. 


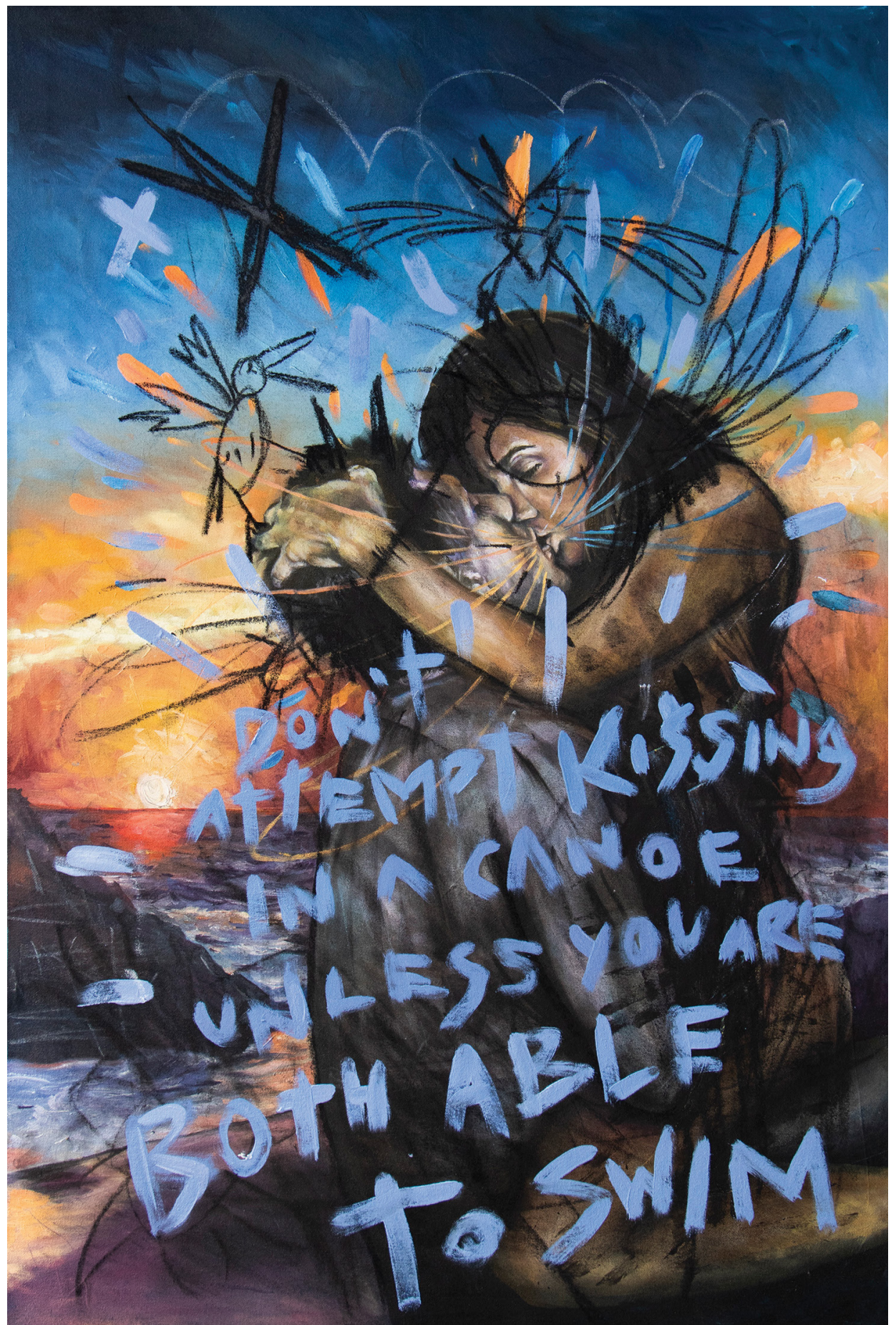

Aprender a nadar, de la serie Mar incendiado (2020). Óleo sobre lino: Xilberto Loera-Núñez. Prohibida su reproducción en obras derivadas. 


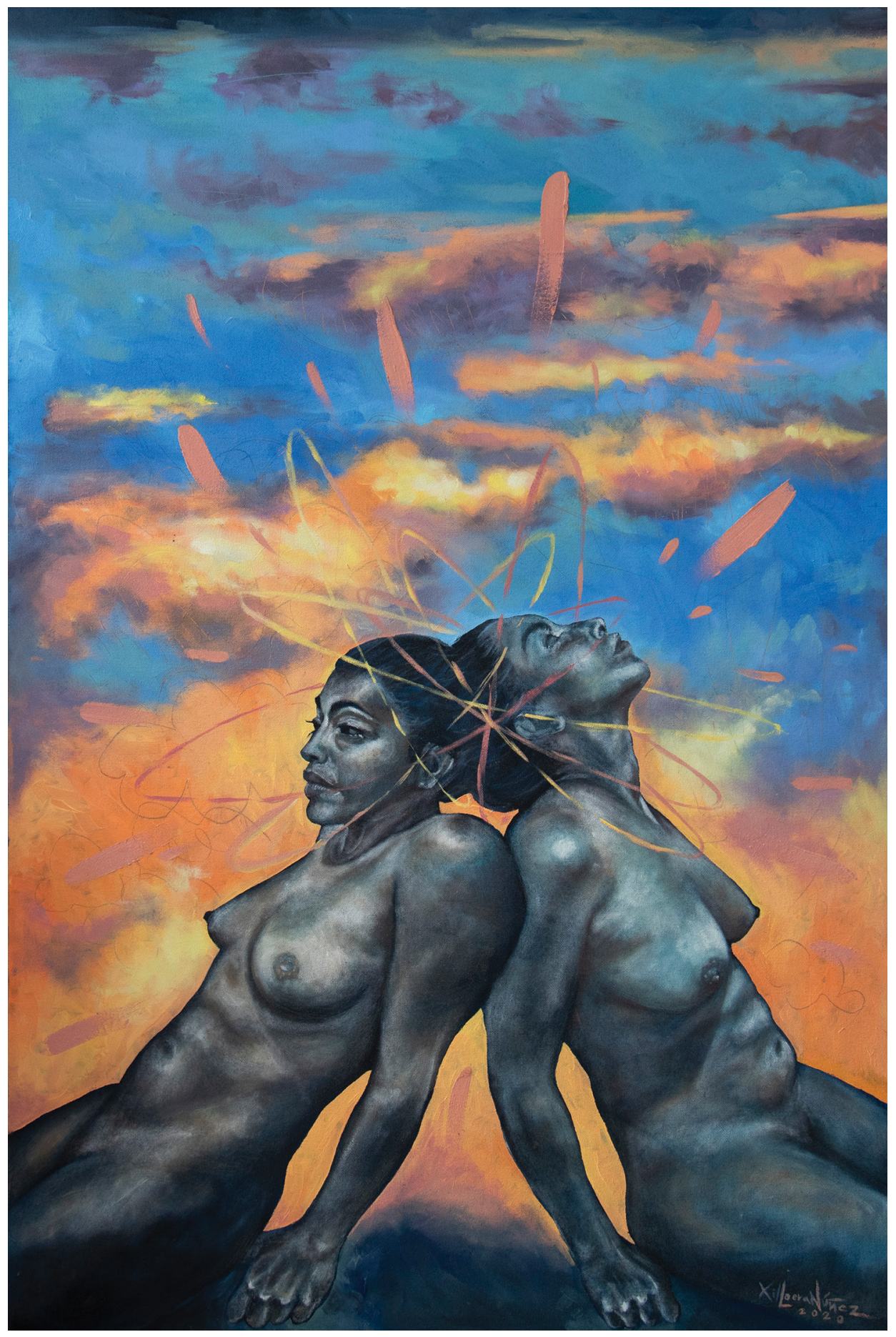

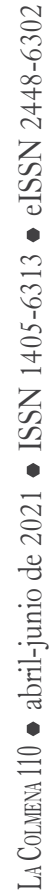

Las dos caras del mar, de la serie Mar incendiado (2020). Óleo sobre lino: Xilberto Loera-Núñez. Prohibida su reproducción en obras derivadas. 


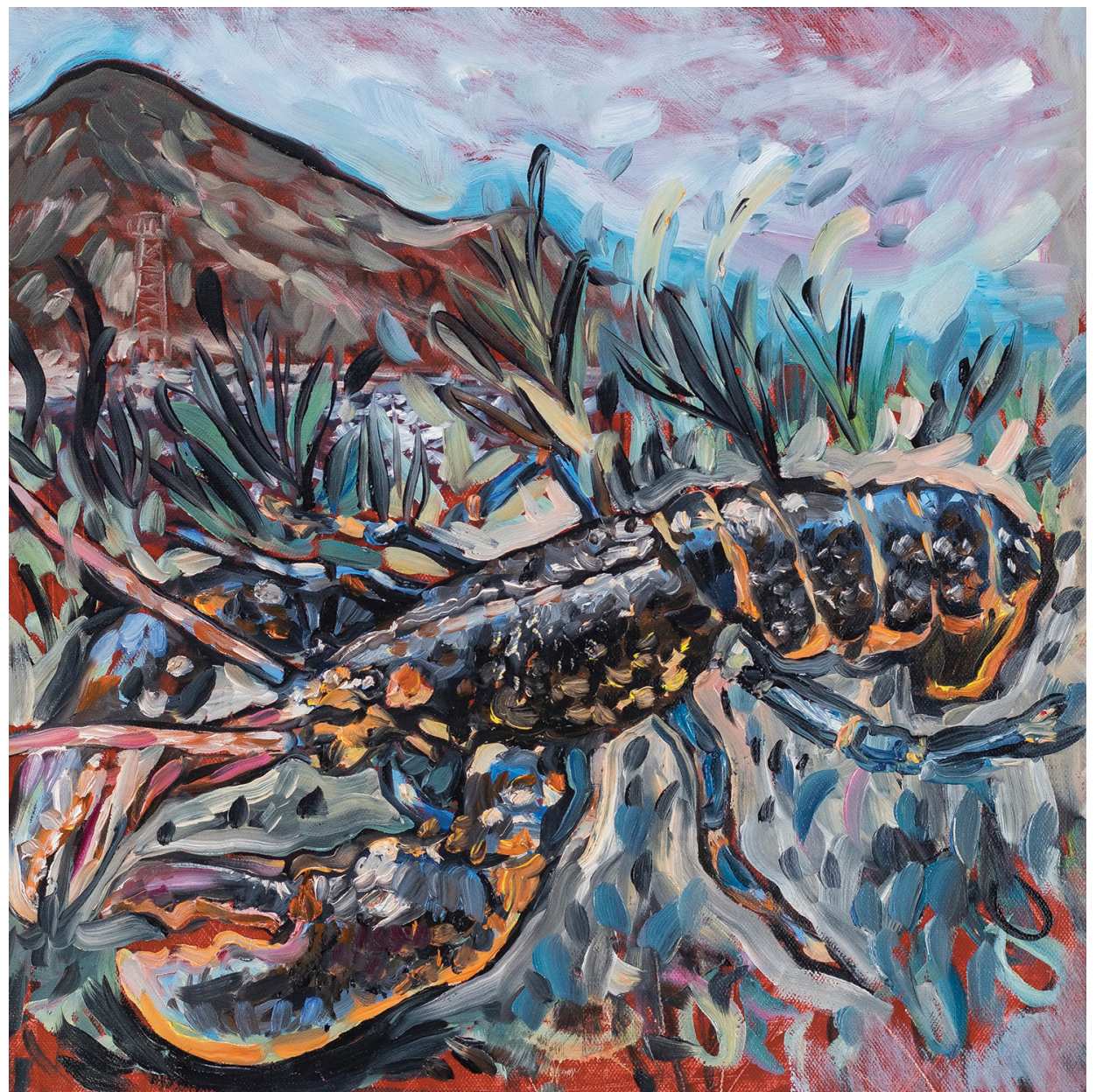

Retrato de la langosta, de la serie Mar incendiado (2021). Óleo sobre lino: Xilberto Loera-Núñez. Prohibida su reproducción en obras derivadas.

Mar incendiado constituye, en síntesis, una afortunada colección de estampas sobre el alma humana, sobre los infinitos y, en ocasiones, imperceptibles lazos que aún en estos tiempos nos vinculan con la naturaleza, sobre nuestras necesidades íntimas e instintos básicos, sobre el silencio y el apego. Esperamos que disfruten, como nosotros, esta fresca propuesta artística y, sobre todo, que la compartan y difundan para seguir haciendo de lo local lo universal. 


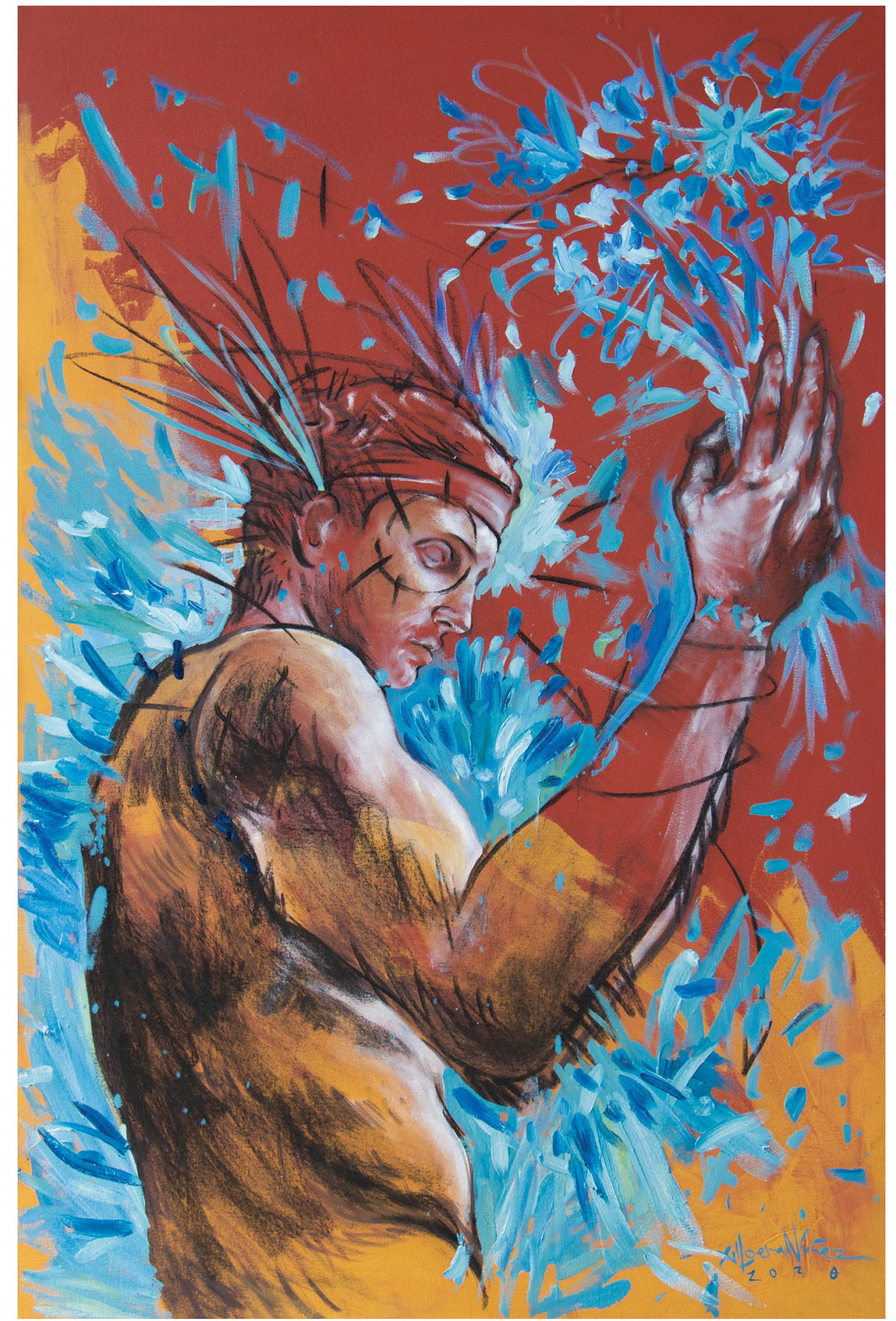

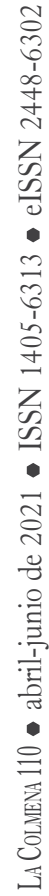

Flores de espuma y la mano que las obsequia, de la serie Mar incendiado (2020). Óleo sobre lino: Xilberto Loera-Núñez. Prohibida su reproducción en obras derivadas. 


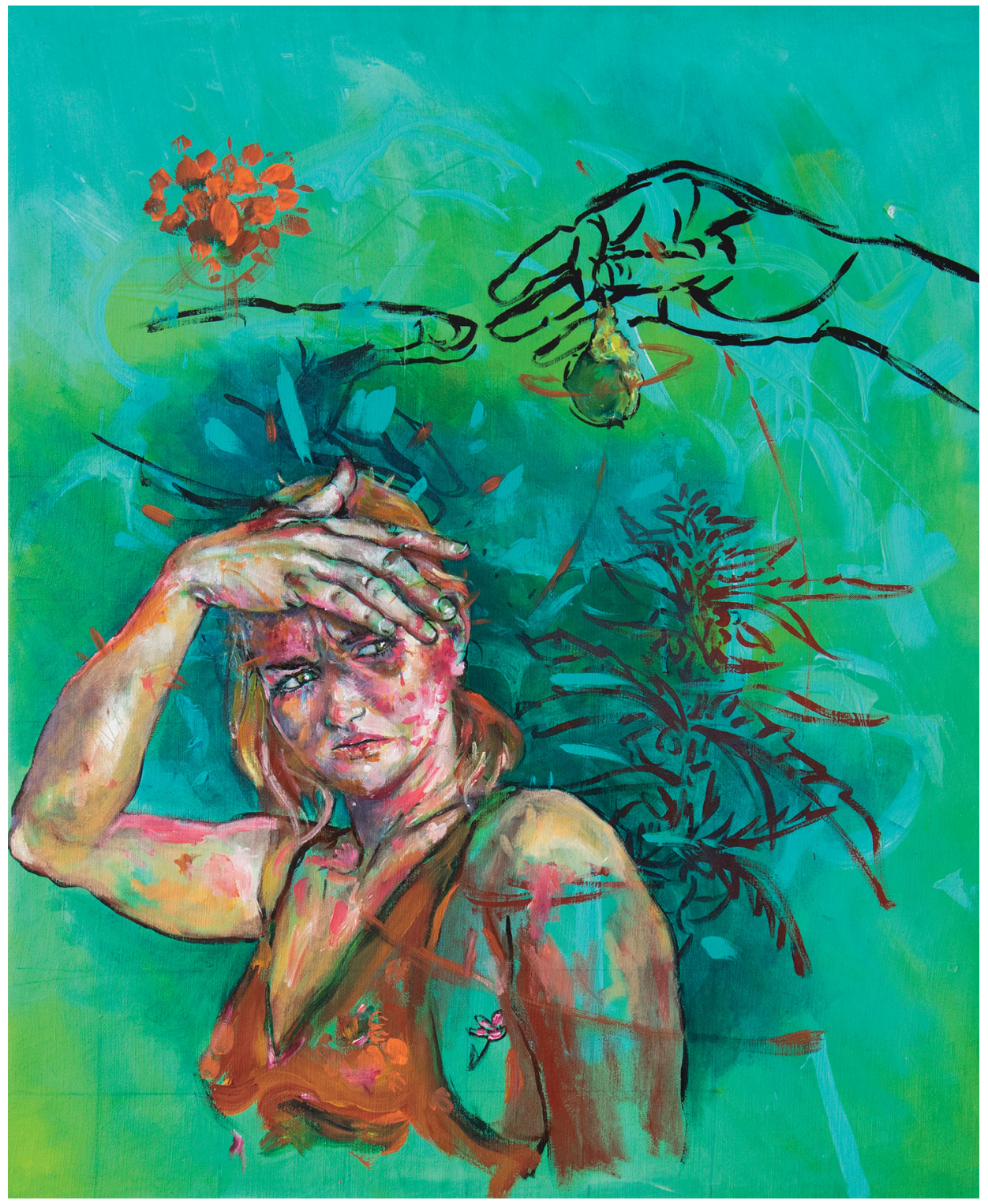

Semilla compartida, de la serie Mar incendiado (2020). Óleo sobre lino: Xilberto Loera-Núñez.

Prohibida su reproducción en obras derivadas. 


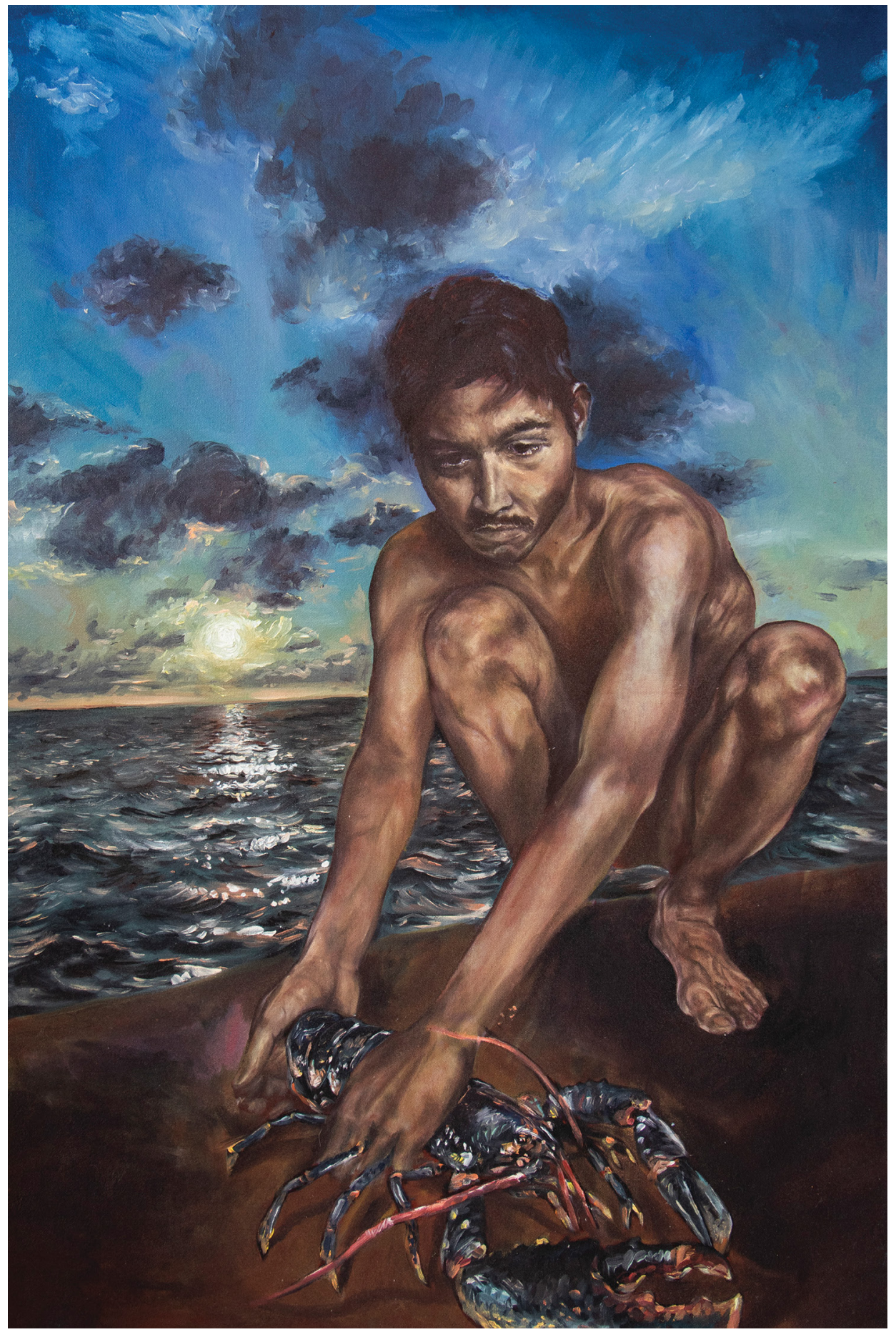

El sueño de la langosta, de la serie Mar incendiado (2020). Óleo sobre lino: Xilberto Loera-Núñez. Prohibida su reproducción en obras derivadas. 


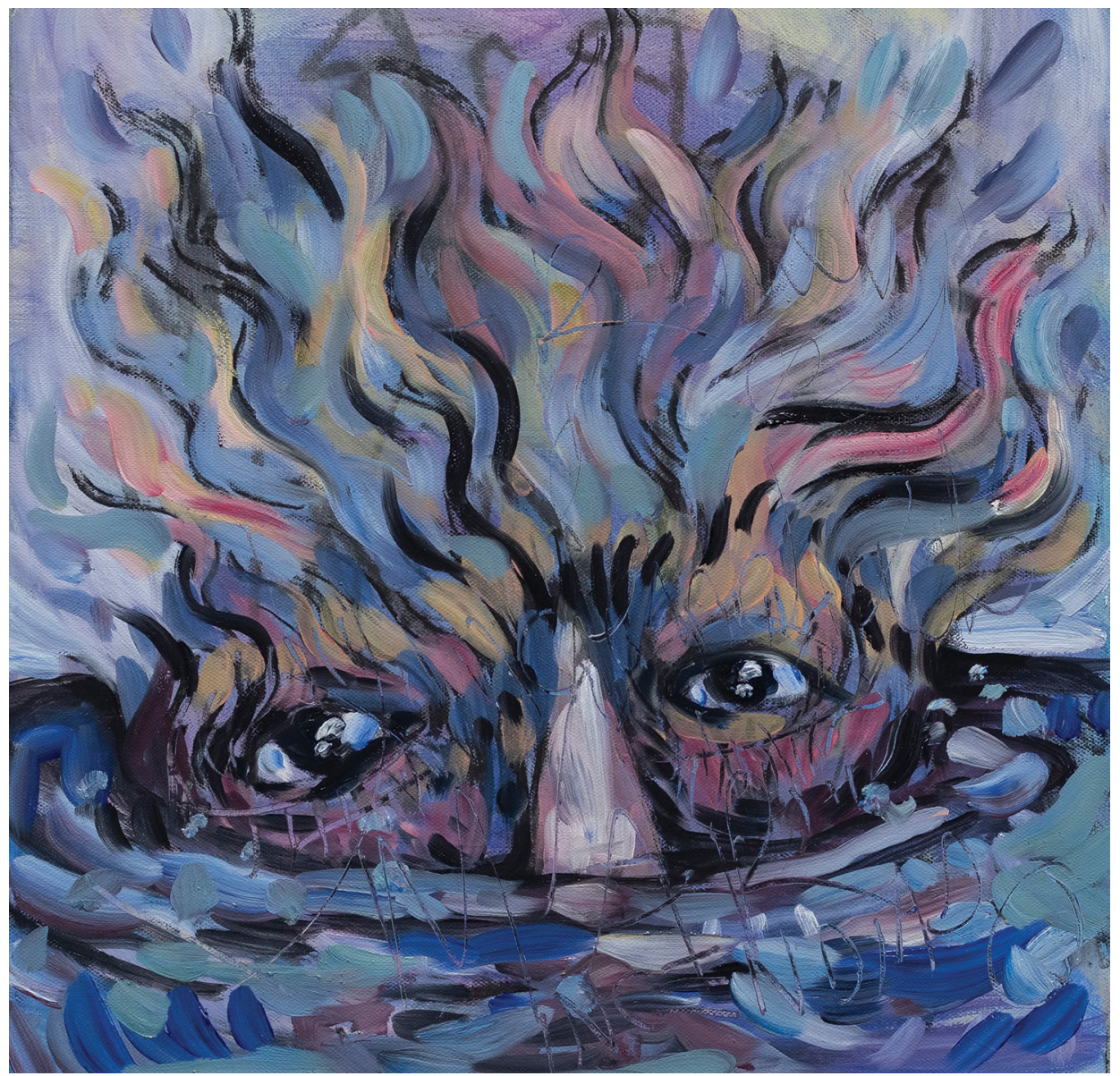

Mar incendiado, de la serie Mar incendiado (2021). Óleo sobre lino: Xilberto Loera-Núñez. Prohibida su reproducción en obras derivadas. 


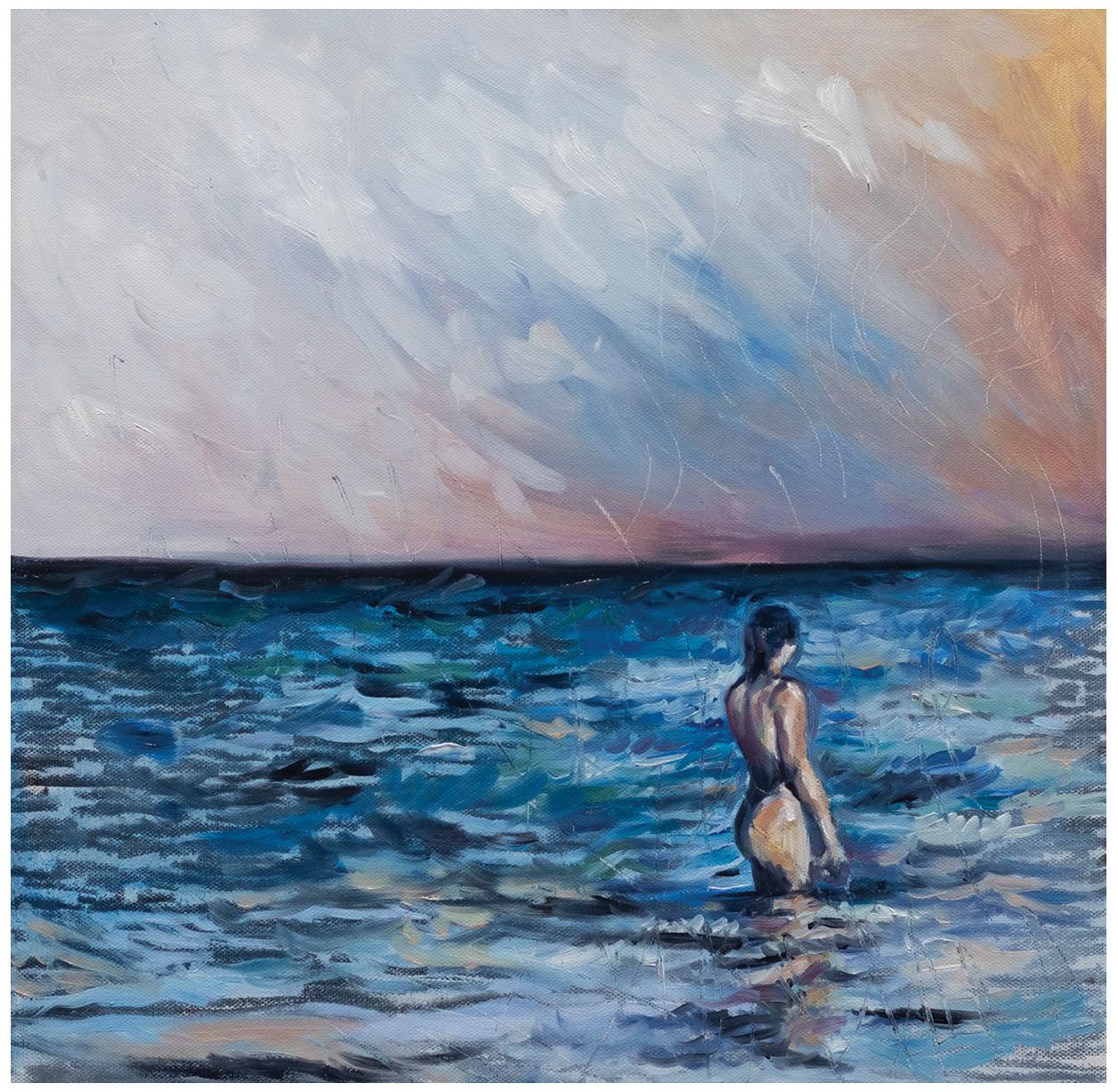

Anochece en el mar, de la serie Mar incendiado (2021). Óleo sobre lino: Xilberto Loera-Núñez.

Prohibida su reproducción en obras derivadas. 


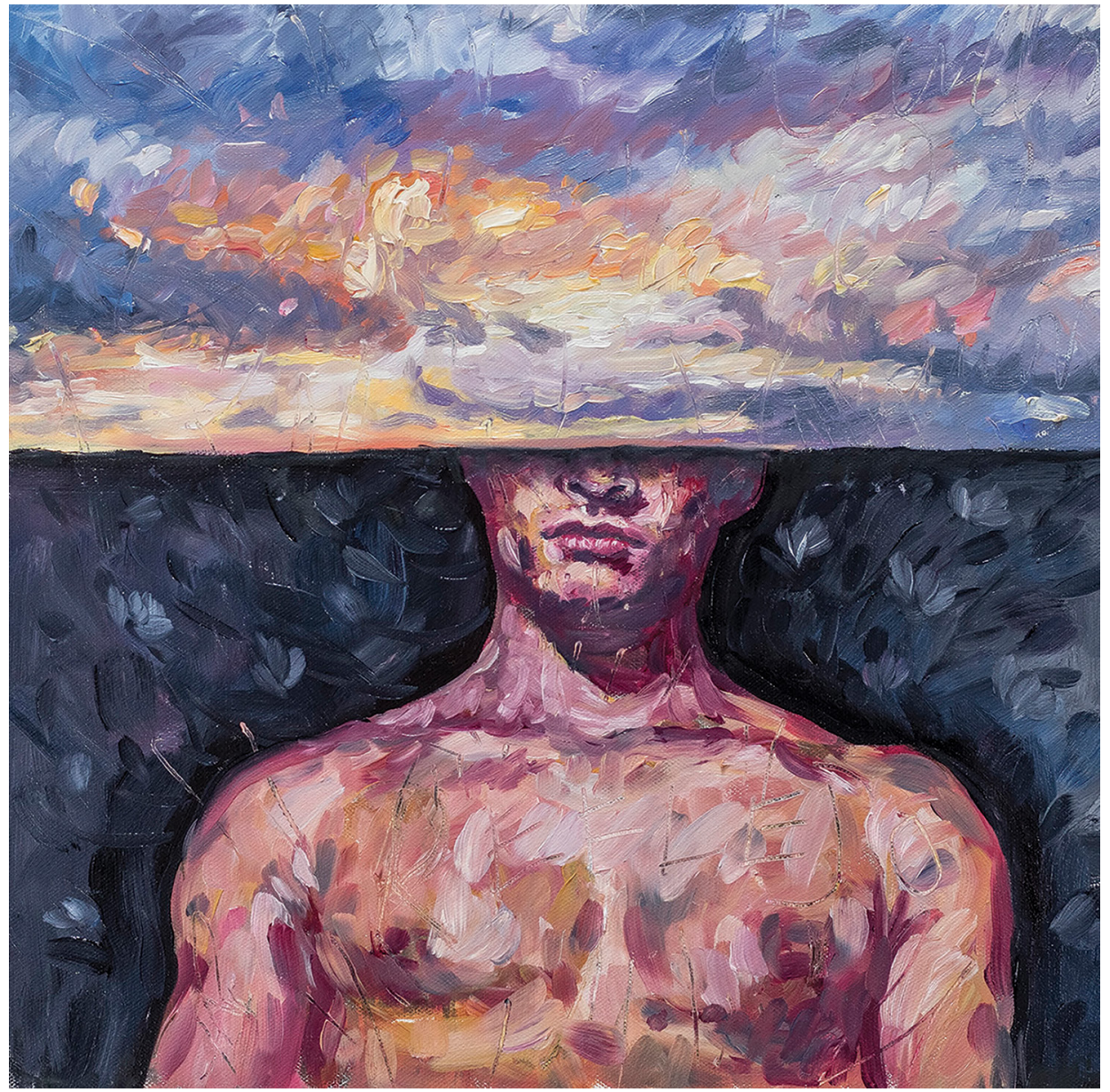

Mira el reflejo de mi cuerpo, de la serie Mar incendiado (2021). Óleo sobre lino: Xilberto Loera-Núñez. Prohibida su reproducción en obras derivadas. 


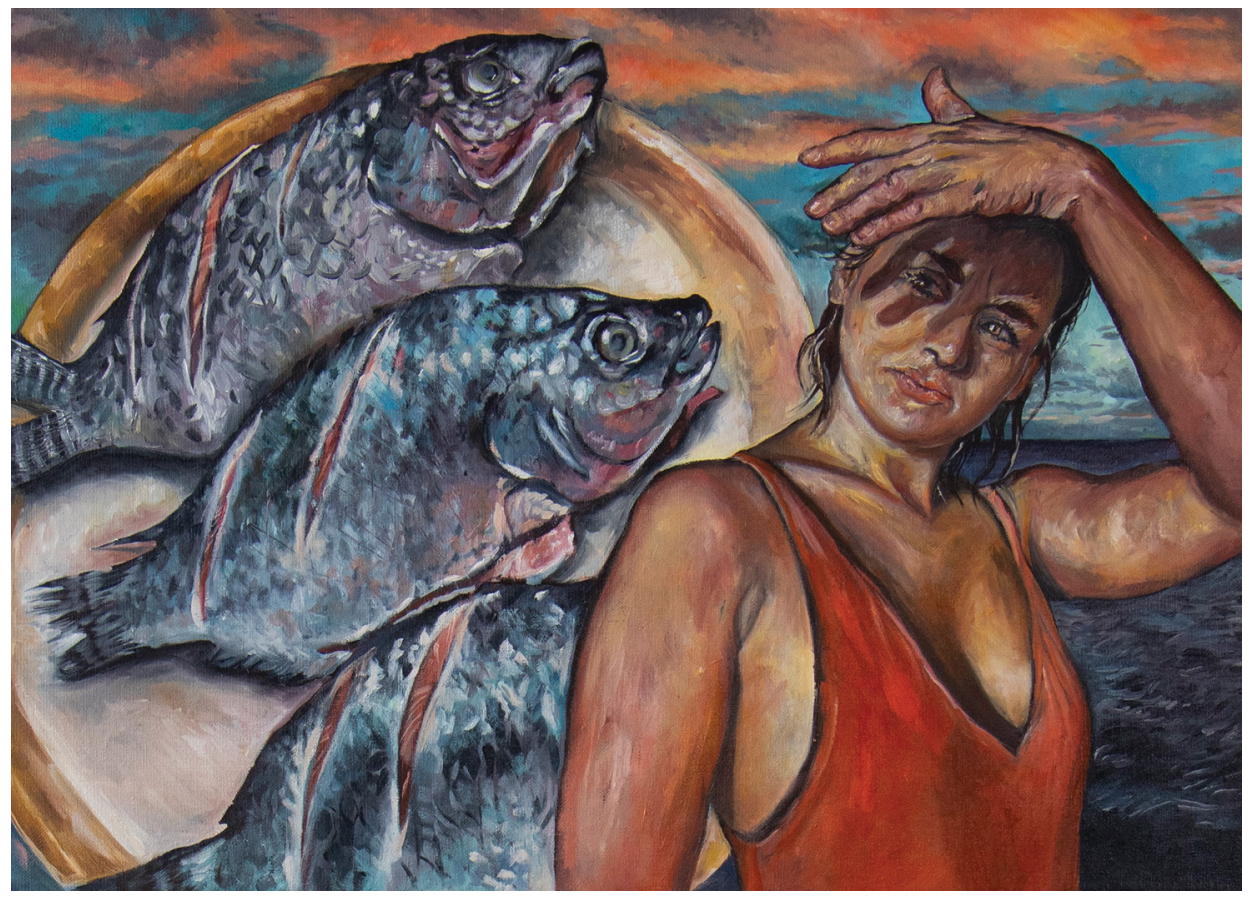

Tres, de la serie Mar incendiado (2020). Óleo sobre lino: Xilberto Loera-Núñez.

Prohibida su reproducción en obras derivadas.

XiLberto L. Núñez (Ciudad de México, 1992). Artista visual radicado en la ciudad de Toluca, ha participado en más de treinta exposiciones colectivas en México, Sudamérica, Estados Unidos y Europa. Tiene tres exposiciones individuales en México y dos en Alemania. Coordina el Chahuixtle, Centro de Experimentación Gráfica, cuyo principal objetivo es el desarrollo artístico a partir de los procesos de impresión tradicionales y no convencionales. Cofundador y coordinador de la Galería Nido, un proyecto orientado a la gestión y difusión del arte emergente en Toluca. Desde 2012 se ha dedicado a la docencia de las artes gráficas. En 2013, realizó estudios independientes sobre escultura en mármol en Atenas y Naxos (Grecia). Ha sido seleccionado dos veces por el Programa de Desarrollo de Estimulación Artística y Creación FOCAEM (México, 2015 y 2017). Su obra forma parte de la colección del Museo de Arte Zuckerman (Estados Unidos) y del Münchner Küntlerhaus (Alemania).

Recibido: 15 de mayo de 2021

Aprobado: 15 de junio de 2021 